\title{
Gambaran Kecerdasan dan Minat Remaja Panti Asuhan X
}

\author{
Linda Wati ${ }^{1}$, Monty P. Satiadarma ${ }^{2}$ dan Untung Subroto ${ }^{3}$ \\ ${ }^{1}$ Fakultas Psikologi, Universitas Tarumanagara Jakarta \\ Email:lindaw@fpsi.untar.ac.id \\ ${ }^{2}$ Fakultas Psikologi, Universitas Tarumanagara Jakarta \\ Email: montys@fpsi.untar.ac.id \\ ${ }^{3}$ Fakultas Psikologi, Universitas Tarumanagara Jakarta \\ Email: untungs@fpsi.untar.ac.id
}

\begin{abstract}
ABSTRAK
Pendidikan bagi seseorang yang tinggal di panti asuhan menjadi hal yang penting demi masa depannya agar mampu bertahan dan menyesuaikan diri dalam lingkungan sosial. Individu yang tinggal di panti asuhan diharapkan dapat diasuh dan dididik dengan keterampilan tertentu agar mereka dapat berprestasi dan bekerja di lingkungan masyarakat. Penelitian ini bertujuan untuk melihat gambaran kecerdasan dan minat remaja Panti Asuhan X di mana hasil yang diperoleh dapat menjadi informasri kepada pengurus panti dalam mengoptimalkan kemampuan anak sesuai dengan kapasitas kecerdasan dan minat mereka. Pengambilan data kecerdasan diperoleh dengan menggunakan tes dan minat diperoleh dengan menggunakan tes Cattell's Culture Fair Intelligence Test (CFIT). Data minat diperoleh dengan menggunakan tes minat Holland. Jumlah subyek penelitian ini adalah 125 remaja usia 13 - 17 tahun. Hasil penelitian menunjukkan bahwa dari 125 subyek, ada 6 (4,8\%) subyek yang memiliki taraf kecerdasan di atas rata-rata, 64 (51,2\%) remaja yang memiliki taraf kecerdasan rata-rata, 34 (27\%) remaja dengan taraf kecerdasan di bawah rata-rata, dan 21 (16,8\%) remaja dengan taraf borderline. Selain itu, berdasarkan tes minat, minat yang paling dominan adalah minat Artistik/seni yaitu sebanyak 29 subyek (23,2\%) dan minat yang paling sedikit disukai adalah minat Realistik sebanyak 8 subyek $(6,4 \%)$.
\end{abstract}

Kata kunci: Kecerdasan, IQ, minat, remaja, panti asuhan.

\section{PENDAHULUAN}

Remaja adalah tahap perkembangan yang berada antara masa kanak-kanak dan dewasa (Feldman, 2000; Berk, 2005; Weiten \& Llyod, 2003) yang dicirikan dengan adanya perubahan yang saling berkaitan antara fisik, kognitif, dan psikososial (Papalia, Olds, \& Feldman, 1998). Pada masa remaja, individu dapat mengalami kematangan kognitif di mana remaja dapat berpikir abstrak. Saat ini, banyak ahli yang melihat remaja secara positif sebagai pribadi yang percaya diri dan memiliki optimisme terhadap masa depan (Santrock, 2014) selain dinilai sebagai masa dengan perilaku berisiko seperti kenakalan remaja, penggunaan zat terlarang/berbahaya, mengemudi tanpa kendali, pencurian, atau perilaku seksual tidak aman (Tursz, 2000).

Berdasarkan teori Piaget, perkembangan kognitif remaja tergolong dalam tahap formal operasional yang biasanya dimulai sejak usia 11 tahun (Santrock, 2014). Cara berpikir remaja sudah tidak terbatas lagi padah hal yang nyata, namun juga konsep asbtrak. Remaja mulai berpikir dengan lebih ideal dan memperhatikan adanya berbagai kemungkinan dari satu permasalahan yang dihadapinya. Mereka berpikir logis dengan memperhatikan hubungan sebab dan akibat dari permasalahan yang dihadapinya (Santrock, 2014).

Perubahan remaja menjadi seorang dewasa tidaklah mudah di mana mereka harus menjadi pribadi yang mandiri dan mengemban tanggung jawab atas diri mereka sendiri (Santrock, 2014). Perubahan dari remaja Sekolah Menengah Atas (SMA) ke sekolah/perguruan tinggi dapat memberi nilai positif di mana remaja merasa dirinya menjadi lebih berkembang, memiliki banyak waktu bersama dengan teman, memiliki kesempatan untuk mencoba banyak kegiatan, menikmati kemandirian/terbebas dari pengawasan dewasa, dan merasa tertantang oleh tuntutan prestasi dan pekerjaan; walau demikian juga dapat menyebabkan banyak tekanan akibat tuntutan tersebut (Santrock, 2014). Mereka perlu bekerja setelah menyelesaikan sekolah dan membiayai dirinya sendiri. 
Holland mengatakan bahwa karakter kepribadian cenderung mengelompok ke dalam satu pola tipe pekerjaan tertentu. Tiap tipe kepribadian berkaitan dengan lingkungan pekerjaan yang paling sesuai/tepat. Ada 6 jenis tipe menurut Holland yaitu Realistik, Investigatif, Artistik/Seni, Sosial, Enterprising, dan Konvensional. Keenam tipe ini sering disebut RIASEC Model (Gregory, 2013,h. 470).

Pekerjaan dari minat Realistik meliputi pekerjaan di luar ruangan atau pekerjaan yang menggunakan peralatan tertentu seperti mekanik, surveyor, petani, dan tukang listrik (Brown \& Brooks, 1991). Biasanya individu dengan minat ini mengalami hambatan dalam kemampuan verbal dan interpersonal, sebaliknya lebih menyukai menggunakan tangannya dalam mengerjakan sesuatu (Gregory, 2011). Pekerjaan dari minat Investigasi meliputi kegiatan ilmiah dan menyelesaikan masalah abstrak seperti ahli biologi, insinyur, atau ahli fisika (Brown \& Brooks, 1991). Individu dengan minat ini adalah seorang pemikir yang berorientasi pada tugastugas tertentu dengan sikap yang tidak konvensional di mana sesuai dengan posisi yang berkaitan dengan ilmiah dan pendidikan (Gregory, 2011).

Pekerjaan yang termasuk minat Artistik meliputi kreativitas dalam menulis, musik, atau keterampilan seni lainnya seperti yang dilakukan seorang penulis, perancang ruangan, dan komposor musik (Nrown \& Brooks, 1991). Mereka biasanya memiliki sifat individualistik dan menghindari situasi yang konvensional/kaku, sebaliknya lebih mencari suasana seni atau yang berubah (Gregory, 2011). Minat sosial meliputi bekerja dengan orang lain dan membantu orang lain, seperti guru, konselor, dan pekerja agama (Brown \& Brooks, 1991). Individu tipe ini akan menggunakan kompetensi sosialnya untuk menyelesaikan masalah dan menyukai kegiatan menolong atau membantu orang lain dijadikan sebagai profesinya (Gregory, 2011).

Minat Enterprising adalah pekerjaan yang meliputi kegiatan memengaruhi, mengarahkan, dan menuntut kemampuan berbicara/komunikasi, seperti sales, business executive, dan pengacara (Brown \& Brooks, 1991).individu dengan minat ini biasanya adalah seorang pemimpin dengan memiliki kemampuan menjual yang baik di mana sesuai dalam dunia usaha dan posisi managerial (Gregory, 2011). Terakhir, minat Konvensional meliputi pekerjaan yang berkaitan dengan angka, detail/rincian, dan data seperti pekerja administrasi dan pegawai bank (Brown \& Brooks, 1991). Mereka cenderung mengikuti dan menyukai aturan yang tersusun rapi/structural (Gregory, 2011).

Remaja akan berkembang baik jika mendapatkan perhatian dari individu dewasa baik orangtua maupun tetangga, guru, atau kerabat lain di mana dapat menjadi teladan bagi remaja. Sebaliknya remaja yang tumbuh dalam kemiskinan perlu mendapatkan perhatian khusus karena mereka tidak berdaya. Mereka rentan mengalami masalah, sulit untuk menjadi orang pembuat keputusan, dan merasa kurang memiliki kekuasaan/pengaruh (Santrock, 2014). Di Jakarta, individu dapat tinggal di sebuah panti asuhan karena berbagai alasan. Salah satu alasannya adalah karena individu tidak memiliki orangtua atau kerabat yang dapat merawat dan mengasuhnya. Selain itu, keterbatasan ekonomi juga menjadi salah satu alasan orangtua memasukkan anaknya ke panti asuhan dengan harapan agar anaknya memiliki masa depan yang lebih baik (AL, Komunikasi pribadi, Februari 2016). Oleh karena itu, seseorang yang tinggal di panti asuhan perlu mendapatkan perhatian. Mereka perlu dipastikan mendapatkan perhatian serius dari dewasa dalam hal pendidikan dan sikap agar dapat berkembang optimal seperti yang diharapkan orangtua atau keluarganya. 
Pemeriksaan psikologis adalah sebagai cara untuk memahami seseorang dalam membuat satu keputusan tertentu. Tujuan pemeriksaan psikologis adalah untuk screening, pemecahan masalah, diagnosis, konseling dan rehabilitasi, serta evaluasi (Sattler, 2001). Psikolog mengukur inteligensi dengan menggunakan tes inteligensi yang kemudian akan memeroleh skor intelligence quatient (IQ). Psikolog Jerman William Stern mengungkapkan istilah IQ pada tahun 1912. IQ terdiri atas usia mental individu dibagi dengan usia kronologis dan kemudian dikalikan 100 (King, 2011). Menurut Gregory, adanya bias budaya dalam tes inteligensi dapat memengaruhi individu. Culture-fair tests adalah tes inteligensi yang merupakan tes bebas pengaruh budaya (King, 2011). Selain itu, pengukuran terhadap minat dapat menggunakan pendekatan Holland dengan dasar teorinya.

Berdasarkan hal tersebut di atas, penelitian bertujuan untuk mendapatkan gambaran kecerdasan dan minat remaja yang berada di Panti Asuhan X. Hal ini bertujuan agar pengurus panti memperoleh informasi anak asuhnya agar memudahkan dalam mengarahkan dan membimbing mereka agar menjadi pribadi yang memiliki masa depan yang lebih baik. Data hasil penelitian dapat digunakan untuk sebagai bahan informasi dalam membuat program atau kegiatan di panti yang memang sesuai dengan pribadi masing-masing anak asuh dan bermanfaat bagi perkembangan mereka.

\section{METODE PENELITIAN}

Subyek penelitian ini adalah 125 remaja di mana terdiri atas 26 laki-laki dan 99 perempuan. Mereka adalah siswa Sekolah Menengah Atas (SMA) yang berusia 13 - 17 tahun di Jakarta yang tinggal di Panti Asuhan X. Beberapa kegiatan yang diadakan Panti Asuhan X selain bersekolah adalah membaca Al-Quran dan Marawis. Subyek adalah remaja yang berasal dari keluarga dengan status ekonomi rendah dan kemudian mendapatkan dukungan dari Panti Asuhan X. Remaja mengikuti kegiatan sehari-hari yang ditentukan oleh Panti Asuhan X. Data mengenai subyek penelitian selengkapnya dapat dilihat pada Tabel 1 dan Tabel 2.

Tabel 1. Gambaran subyek berdasarkan usia

\begin{tabular}{ccc}
\hline Usia & Frekuensi & Persentase \\
\hline 13 & 1 & .8 \\
14 & 23 & 18.4 \\
15 & 49 & 39.2 \\
16 & 39 & 31.2 \\
17 & 13 & 10.4 \\
Total & 125 & 100.0 \\
\hline
\end{tabular}

Tabel 2. Gambaran subyek berdasarkan tingkat pendidikan

\begin{tabular}{ccc} 
Pendidikan & Frekuensi & Persentase \\
\hline MA & 10 & 8.0 \\
SMA & 33 & 26.4 \\
SMK & 82 & 65.6 \\
Total & 125 & 100.0 \\
\hline
\end{tabular}

Penelitian ini menggunakan metode kuantitatif dengan teknik deskriptif di mana akan menggambarkan dua variabel yang akan diukur. Data dioleh dan dianalisis secara statistik deskriptif. Variabel yang akan diukur adalah variabel kecerdasan dan variabel minat subyek. Jadi, penelitian ini bertujuan untuk memberikan gambaran mengenai kecerdasan dan minat 
remaja yang tinggal di Panti Asuhan X. Variabel kecerdasan diukur dengan menggunakan tes Cattell's Culture Fair Intelligence Test (CFIT) dan memperoleh skor IQ (Intelligence Quotient). Variabel minat diukur dengan menggunakan tes minat Holland.

\section{HASIL PENELITIAN}

Berdasarkan hasil pemeriksaan kecerdasan dengan menggunakan tes CFIT, diperoleh hasil ada 6 $(4,8 \%)$ subyek yang memiliki IQ di atas rata-rata, ada 64 (51\%) subyek yang memiliki IQ ratarata, ada $34(27,2 \%)$ subyek yang memiliki IQ di bawah rata-rata, dan $21(16,8 \%)$ subyek yang memiliki IQ Borderline. Selain itu, tidak ada subyek laki-laki yang memeroleh IQ dengan kategori di atas rata-rata. Data selengkapnya dapat dilihat pada Tabel 3.

Tabel 3. Gambaran IQ berdasarkan jenis kelamin

\begin{tabular}{lccc}
\hline Kelompok IQ & \multicolumn{2}{c}{ Jenis Kelamin } & Total \\
\cline { 2 - 3 } & Laki-laki & Perempuan & \\
\hline Di atas rata-rata & 0 & 6 & 6 \\
Rata-rata & 13 & 51 & 64 \\
Di bawah rata-rata & 7 & 27 & 34 \\
Borderline & 6 & 15 & 21 \\
Total & 26 & 99 & 125 \\
\hline
\end{tabular}

Berdasarkan hasil pemeriksaan minat subyek dengan menggunakan tes Holland, diperoleh hasil bahwa ada $8(6,4 \%)$ subyek yang memiliki minat Realistik, 27 (21,6\%) subyek yang memiliki minat Investigasi, $29(23,2 \%)$ subyek yang memiliki minat Artistik/seni, 22 (17,6\%) subyek yang memiliki minat Sosial, 19 (15,2\%) yang memiliki minat Enterprising, dan 20 (16\%) yang memiliki minat Konvensional. Data selengkapnya dapat dilihat pada Tabel 4.

Tabel 4. Gambaran minat berdasarkan persentasenya

\begin{tabular}{lcc} 
& Frekuensi & Persentase \\
\hline Realistik & 8 & 6.4 \\
Enterprising & 19 & 15.2 \\
Konvensional & 20 & 16.0 \\
Sosial & 22 & 17.6 \\
Investigasi & 27 & 21.6 \\
Artistik/Seni & 29 & 23.2 \\
Total & 125 & 100.0 \\
\hline
\end{tabular}

Hasil penelitian juga menemukan pada subyek dengan minat realistik terdiri atas 7 laki-laki dan 1 perempuan. Subyek yang memiliki minat investigasi terdiri atas 2 laki-laki dan 25 perempuan. Kemudian, pada minat artistik/seni, ada 4 laki-laki dan 25 perempuan. Ada 2 subyek laki-laki dan 20 subyek perempuan yang memiliki minat sosial. Lalu ada 8 subyek laki-laki dan 11 subyek perempuan yang memiliki minat Enterprising. Terakhir, ada 3 subyek laki-laki dan 17 subyek perempuan dengan minat konvensional. Data selengkapnya dapat dilihat pada Tabel 5.

Hasil penelitian juga menemukan bahwa dari 8 subyek yang memiliki minat Realistik, tidak ada subyek yang memiliki skor IQ di atas rata-rata. Dari 27 subyek yang memiliki minat pada kegiatan investigasi, ada 2 subyek yang memiliki IQ di atas rata-rata, 21 subyek memiliki IQ rata-rata, 3 subyek memiliki IQ di bawah rata-rata, dan 1 subyek yang memiliki IQ borderline. Dari 29 subyek yang memiliki minat pada kegiatan seni, ada 2 subyek yang memiliki IQ di atas rata-rata, 12 subyek memiliki IQ rata-rata, 7 subyek memiliki IQ di bawah rata-rata, dan 8 
subyek memiliki IQ borderline. Dari 22 subyek yang memiliki ketertarikan pada kegiatan sosial, ada 1 subyek yang memiliki IQ di atas rata-rata, 7 subyek memiliki IQ rata-rata, 11 subyek memiliki di bawah rata-rata, dan 3 subyek memiliki IQ borderline. Selanjutnya pada minat Enterprising, tidak ada subyek memiliki IQ di atas rata-rata. Ada 7 subyek yang memiliki IQ rata-rata, 4 subyek dengan IQ di bawah rata-rata, dan 8 subyek dengan IQ borderline. Terakhir, tidak ada subyek yang memiliki IQ borderline, ada 1 subyek memiliki IQ di atas rata-rata, 13 subyek dengan IQ rata-rata, dan 6 subyek dengan IQ di bawah rata-rata. Data selengkapnya dapat dilihat pada Tabel 6 .

Tabel 5. Gambaran minat berdasarkan jenis kelamin

\begin{tabular}{lccc}
\hline \multirow{2}{*}{ Minat } & \multicolumn{2}{c}{ Jenis Kelamin } & \multirow{2}{*}{ Total } \\
\cline { 2 - 3 } & Laki-laki & Perempuan & \\
\hline Realistik & 7 & 1 & 8 \\
Enterprising & 8 & 11 & 19 \\
Konvensional & 3 & 17 & 20 \\
Sosial & 2 & 20 & 22 \\
Investigasi & 2 & 25 & 27 \\
Artistik/Seni & 4 & 25 & 29 \\
Total & 26 & 99 & 125 \\
\hline
\end{tabular}

Tabel 6. Gambaran minat berdasarkan ketegori IQ

\begin{tabular}{|c|c|c|c|c|c|}
\hline \multirow[b]{2}{*}{ Minat } & \multicolumn{4}{|c|}{ Kategori IQ } & \multirow[b]{2}{*}{ Tota } \\
\hline & Borderline & $\begin{array}{c}\text { Di bawah } \\
\text { rata-rata }\end{array}$ & Rata-rata & $\begin{array}{c}\text { Di atas rata- } \\
\text { rata }\end{array}$ & \\
\hline Realistik & 1 & 3 & 4 & 0 & 8 \\
\hline Enterprising & 8 & 4 & 7 & 0 & 19 \\
\hline Konvensional & 0 & 6 & 13 & 1 & 20 \\
\hline Sosial & 3 & 11 & 7 & 1 & 22 \\
\hline Investigasi & 1 & 3 & 21 & 2 & 27 \\
\hline Artistik/Seni & 8 & 7 & 12 & 2 & 29 \\
\hline Total & 21 & 34 & 64 & 6 & 125 \\
\hline
\end{tabular}

\section{KESIMPULAN DAN SARAN}

Berdasarkan hasil pemeriksaan terhadap potensi kecerdasan secara menyeluruh terhadap subyek yang tinggal di Panti Asuhan X, maka ditemukan dari 125 subyek hanya ada 64 subyek dengan IQ rata-rata dan 6 subyek dengan IQ di atas rata-rata. Hal ini menunjukkan bahwa kemampuannya melebihi subyek lainnya yang seusianya. Sebaliknya ada 34 subyek yang memiliki tingkat kecerdasan di bawah rata-rata dan bahkan ada 21 subyek dengan kategori Borderline. Skor ini menunjukkan bahwa kemampuan subyek berada di bawah rata-rata orang lain yang seusianya.

Berdasarkan hasil pemeriksaan terhadap minat subyek di Panti Asuhan X, minat Artistik/seni adalah yang paling dominan di mana ada 29 subyek $(23,2 \%)$ yang tertarik pada minat ini. Dari 29 subyek, ada 2 subyek dengan IQ di atas rata dan 12 subyek dengan IQ rata-rata. Dari 29 subyek tersebut, 25 subyek berjenis kelamin perempuan dan 4 subyek berjenis kelamin laki-laki. Sebaliknya, minat yang tidak banyak disukai oleh subyek di Panti Asuhan X adalah minat Realistik $(6,4 \%)$ dengan 8 subyek. Tidak ada subyek yang memiliki IQ di atas rata-rata da nada 4 subyek dengan IQ rata-rata yang memiliki minat pada area realistik. Dari 8 subyek tersebut, hanya ada 1 subyek yang berjenis kelamin perempuan dan 7 subyek berjenis kelamin laki-laki. 
Berdasarkan hasil temuan di mana dari 125 subyek di Panti Asuhan X, ada 70 subyek yang memiliki taraf kecerdasan bagi karena berada dalam taraf rata-rata dan di atas rata-rata. Sedangkan sisanya berada dalam taraf di bawah rata-rata dan borderline. Hal ini menunjukkan bahwa ada hampir separuh dari subyek remaja di Panti Asuhan X memiliki taraf kecerdasan di bawah rata-rata. Hal ini dapat disebabkan karena latar belakang keluarga yang kurang mendukung mengingat subyek berasal dari kondisi status ekonomi rendah atau sudah tidak memiliki orangtua lagi. Selain itu, pengarahan dan bimbingan dari orang dewasa juga memengaruhi kondisi ini. Seperti yang dikemukakan oleh Santrock (2004) bahwa remaja akan berkembang optimal jika mendapatkan perhatian individu dewasa dan faktor kemiskinan dapat memengaruhi sikap remaja secara menyeluruh.

Berdasarkan hasil temuan, ada 55 subyek yang memiliki taraf kecerdasan di bawah rata-rata. Hal ini menunjukkan bahwa kemampuannya berada di bawah remaja lain yang seusianya. Artinya potensi kecerdasan 55 subyek di Panti Asuhan X kurang berkembang dengan baik seperti yang seharusnya. Menurut Piaget, seharusnya remaja berada dalam tahap formal operasional di mana ia sudah mampu berpikir abstrak, logis, dan mampu menganalisa hubungan sebab akibat dari satu masalah yang dihadapinya (Santrock, 2014). Walau demikian, hal ini tidak terjadi pada 55 subyek di Panti Asuhan X. Ke-55 subyek membutuhkan pengarahan dan bimbingan untuk memahami satu konsep abstrak atau ketika melakukan analisa terhadap suatu permasalahan.

Hasil temuan juga menunjukkan bahwa minat yang dominan pada subyek di Panti Asuhan X adalah pada kegiatan artistik/seni. Hal ini dapat disebabkan karena kegiatan di panti pun melibatkan unsur seni juga selain aspek religius melalui kegiatan Marawis yang menjadi salah satu kegiatan rutin di panti. Beberapa subyek juga menyukai kegiatan Marawis. Sebaliknya, kegiatan realistik kurang diminati oleh subyek remaja di Panti Asuhan X. Hal ini dapat disebabkan karena kegiatan yang diterapkan di panti cenderung ke arah religius dan seni sehingga kegiatan yang terkait realistik menjadi tidak banyak dilakukan. Selain itu, adanya kegiatan sekolah serta kegiatan membaca Al Quran dan Marawis membuat waktu yang digunakan subyek untuk melakukan kegiatan realistik menjadi berkurang. Akibatnya subyek menjadi kurang menyukai kegiatan tersebut karena kurangnya kesempatan untuk melakukannya.

Berdasarkan hal tersebut di atas, ada beberapa saran yang dapat peneliti berikan. Pertama, subyek di Panti Asuhan X perlu mendapatkan pengarahan dan bimbingan dari pengurus dalam belajar dan berperilaku sehari-hari, terutama khususnya pada subyek yang memiliki potensi kecerdasan di bawah rata-rata. Ketika melakukan bimbingan dan pengarahan, sebaiknya menggunakan Bahasa yang sederhana sehingga mudah dimengerti subyek. Penggunaan contoh nyata atau secara langsung juga akan sangat membantu. Kedua, pengurus panti perlu membuat kegiatan belajar bersama secara rutin. Melalui kegiatan belajar bersama diharapkan adanya kerjasama di antara subyek untuk saling membantu subyek lain yang mungkin tidak paham dengan pelajarannya. Ketiga, pengurus panti juga sebaiknya mengadakan kegiatan untuk melatih dan meningkatkan keterampilan. Misalnya pelatihan memasak, membuat kue, salon, menjahit, membuat kerajinan tangan, memperbaiki peralatan elektronik, pertukangan, atau perkebunan. Keempat, pengurus dapat memberikan pujian atau penghargaan ketika subyek berhasil dalam prestasi akademik atau ketika bersikap baik. Hal ini akan meningkatkan rasa keyakinan, rasa percaya diri, dan kebermaknaan dalam diri subyek agar mereka dapat berkembang lebih maju lagi. 


\section{Ucapan Terima Kasih}

Peneliti mengucapkan terima kasih kepada pengurus Panti Asuhan X yang telah membantu dalam proses pengambilan data penelitian. Selain itu peneliti juga mengucapkan terima kasih kepada asisten peneliti yang juga turut membantu dalam pengambilan data tes kepada subyek.

\section{REFERENSI}

Berk, L. E. (2005). Infants, children, and adolescents 5th edition. Boston: Pearson Education.

Brown, D., \& Brooks, L. (1991). Career counseling techniques. Needham Heights, MA: Allyn and Bacon.

Feldman, R. S. (2000). Development across the life span 2nd edition. Upper Saddle River, NJ: Prentice-Hall.

Gregory, R. J. (2011). Psychological testing: History, principles, and applications 6th edition. Upper Saddle River, NJ: Pearson.

Gregory, R. J. (2013). Psychological testing: History, principles, and applications 7th edition. Upper Saddle River, NJ: Pearson.

King, L. (2011). The science of psychology: An appreciative view 2nd edition. New York, NY: McGrw-Hill.

Papalia, D. E., Olds, S. W, \& Feldman, R. D. (1998). Human development 7th edition. New York: McGraw Hill Companies.

Sattler, J. M. (2001). Assessment of children: Cognitive application 4th edition. San Diego: Jerome M. Sattler.

Tursz, A. (2000). Adolescents' risk taking behavior, myth or reality: Evidence from international data. In D. Mohan \& G. Tiwari (Eds.), Injury prevention and control (pp. 149-163). New York, NY: Taylor \& Francis

Weiten, W. \& Lloyd, M. A. (2003). Psychology applied to modern life 7th edition. Belmont, CA: Wadsworth/Thomson Learning 